\title{
Cytoprotective effect of Streptococcus thermophilus against oxidative stress mediated by a novel peroxidase (EfeB)
}

\author{
Yue Wang, ${ }^{*}$ Honghong $\mathrm{Li},{ }^{*}$ Tiejun $\mathrm{Li}, \dagger$ Huiying He, ${ }^{*}$ Xue Du, $\uparrow$ Xiaowei Zhang, $†$ and Jian Kong*1 \\ *State Key Laboratory of Microbial Technology, Shandong University, Jinan, P. R. China 250100 \\ †Health Science Exchange and Service Center of Jinan, Jinan, P. R. China 250100
}

\begin{abstract}
Streptococcus thermophilus is one of the most important starter species used in the dairy industry and exhibits several beneficial properties for the hosts. However, knowledge of the mechanism of its beneficial effect is still limited. The objective of this study was to investigate the cytoprotective effect of $S$. thermophilus CGMCC 7.179 with a novel peroxidase (EfeB) against oxidative stress in human intestinal epithelial cells, HT29. Previously, we identified EfeB in S. thermophilus CGMCC 7.179, which could provide protection when growing at aerobic conditions. Here, we found that, when exposed to $15 \mathrm{mM} \mathrm{H} \mathrm{H}_{2} \mathrm{O}_{2}$, the cell viability of the efeB mutant (ST1314) was much lower than that of strain CGMCC 7.179, and the 1,1-diphenyl-2-picrylhydrazyl radical scavenging activity of strain ST1314 decreased by $15 \%$. When co-incubated with HT-29 cells, strain CGMCC 7.179 stimulated the enhancement of the major antioxidant enzyme activities (superoxide dismutase, glutathione peroxidase, and catalase) in HT-29 cells under $2 \mathrm{mM} \mathrm{H} \mathrm{H}_{2} \mathrm{O}_{2}$-induced oxidative stress, whereas the active decrease of those antioxidant enzymes was observed in strain ST1314. In addition, the intracellular reactive oxygen species content in HT-29 cells co-incubated with strain CGMCC 7.179 was lower than that with strain ST1314 under the same oxidative stress. Furthermore, the protein content of nuclear factor erythroid 2-related factor 2 (Nrf2) in HT-29 cells following strain CGMCC 7.179 treatment was 1.4fold higher than that with strain ST1314 treatment, and the increased transcription levels of Nrf2-related antioxidant enzyme genes were also observed in strain CGMCC 7.179 cells. All of these results demonstrated that S. thermophilus CGMCC 7.179 enhanced cellular antioxidant responses and endowed host cells with pro-
\end{abstract}

Received February 16, 2018.

Accepted April 18, 2018.

${ }^{1}$ Corresponding author: kongjian@sdu.edu.cn tective effects against oxidative stress mediated by the peroxidase EfeB.

Key words: Streptococcus thermophilus, peroxidase EfeB, oxidative stress, intestinal epithelial cell

\section{INTRODUCTION}

The occurrence of oxidative stress is due to an imbalance between production of reactive oxygen species (ROS) and antioxidant capabilities of cellular antioxidants in a biological system (Halliwell, 2009). Although oxidation is essential to many living organisms for the production of energy to promote biological processes, excessive ROS and oxidation products cause oxidative damage to cellular biomolecules such as proteins, nucleic acids, and lipids, impairing their biological functions (Berlett and Stadtman, 1997). Thus, oxidative stress is related to the pathogenesis of multiple chronic health problems and diseases, including inflammation, agerelated diseases, and cancers (Storz, 2005; Valko et al., 2007; Spooner and Yilmaz, 2011). Substantial evidence has indicated that generation of an enhanced level of ROS leads to the development of some chronic intestinal inflammatory diseases and is commonly implicated in the pathogenesis of inflammatory bowel diseases, which have been recognized as chronic inflammatory disorders of the human gastrointestinal tract (Kruidenier and Verspaget, 2002; Zhu and Li, 2012). For this, the human body has evolved various cellular defense mechanisms to protect organisms from ROS overproduction and oxidative stress. The key antioxidant enzymes superoxide dismutase (SOD), glutathione peroxidase (GSH-px), and catalase (CAT) are able to trigger these mechanisms against oxidative burst and offer protection to cells and tissues against oxidative injury (BonnefontRousselot et al., 2000). Furthermore, nuclear factor erythroid 2-related factor 2 (Nrf2), known as a major regulator of a cellular defense system against oxidative stress, is able to control the antioxidant response element (ARE)-dependent gene regulation to respond to oxidative stress in human cells (Jaiswal, 2004).

It has been claimed repeatedly that some microorganisms, particularly the species of lactic acid bacteria 
(LAB), which are widely used in the manufacture of fermented products, possess antioxidant properties, and confer a health benefit for the hosts (Pagnini et al., 2010; Martarelli et al., 2011). Considered a generally recognized as safe (GRAS) species (Hols et al., 2005), Streptococcus thermophilus is the most frequently used species in the fermentation of yogurt and cheeses as starter cultures in the dairy industry (Morelli L, 2014). The recovery of $S$. thermophilus in feces of human volunteers consuming yogurt has definitively established that this bacterium remains alive during its transit through the digestive tract (Mater et al., 2005; Elli et al., 2006). Furthermore, it has been reported that $S$. thermophilus in yogurt cultures could promote lactose digestion in lactose-intolerant patients and also stimulate the gut immune system (Rabot et al., 2010; Savaiano, 2014). Although $S$. thermophilus exhibits several beneficial properties for the host, only a few studies have been focused on the mechanism of its beneficial effects.

Streptococcus thermophilus has evolved a specific inducible defensive system against ROS damage to make itself grow in the presence of oxygen and survive in the presence of a low concentration of $\mathrm{H}_{2} \mathrm{O}_{2}$ (Thibessard et al., 2001b). Those defensive systems were in conjunction with the NADH oxidase, SOD, glutathione, thioredoxin, and other antioxidant systems in $S$. thermophilus (Chang and Hassan, 1997; Hols et al., 2005; Marco et al., 2013; Lu and Holmgren, 2014; Wang et al., 2017). Previously, we identified a novel dye-decolorizing peroxidase EfeB, the only peroxidase found in $S$. thermophilus, which played a role in protecting cells of $S$. thermophilus from oxidative stress, with the assistance of the Tat system (Zhang et al., 2015). The antioxidant effect of LAB is one of the most important mechanism for health benefit of the host; thus, in this study, we aimed to investigate the cytoprotective effect of $S$. thermophilus GCMCC 7.179 against oxidative stress in human intestinal epithelial cells, and the mechanism mediated by EfeB.

\section{MATERIALS AND METHODS}

\section{Bacterial Strains and Culture Conditions}

Streptococcus thermophilus CGMCC7.179, originally isolated from a traditional yogurt of Inner Mongolia, China, and its efeB isogenic mutant ST1314 (Zhang et al., 2015) were used in this study. Streptococcus thermophilus strains were propagated in M17 broth (Oxoid, Basingstoke, UK) supplemented with 1\% (wt/vol) of lactose (LM17 broth) at $42^{\circ} \mathrm{C}$ without shaking. All cultures were grown for $12 \mathrm{~h}$ (stationary phase) before being used in the experiments.

\section{Detection of Cell Survival Against Oxidative Stress}

Cell survival under $\mathrm{H}_{2} \mathrm{O}_{2}$ treatment was detected as described previously (Thibessard et al., 2001a). Briefly, after overnight static incubation at $42^{\circ} \mathrm{C}, S$. thermophilus CGMCC7.179 and ST1314 were 2\% inoculated into $5 \mathrm{~mL}$ of fresh LM17 broth and incubated statically at $42^{\circ} \mathrm{C}$. When the optical density at $600 \mathrm{~nm}$ reached 0.4 ,

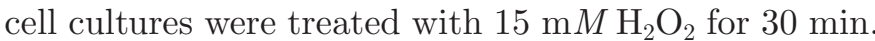
The survival of $S$. thermophilus cells against oxidative stress was calculated by pipetting samples onto plates and determining the numbers of colony-forming units according to a previous method (Zhang et al., 2015).

\section{Scavenging Activity of 1,1-Diphenyl-2- Picrylhydrazyl Radical}

The 1,1-diphenyl-2-picrylhydrazyl (DPPH) radical scavenging activity of cell-free extract was analyzed as described previously with minor modifications (Lin and Chang, 2000). Cell-free extracts were obtained from cell suspensions by shaking in a bullet blender of $0.1 \mathrm{~g}$ of glass beads for $30 \mathrm{~s}, 3$ times, and centrifuged at 13,000 $\times g$ for 10 min at $4^{\circ} \mathrm{C}$ to remove the cell debris. The protein concentration of cell-free extracts was determined by UV-Vis Spectrophotometer Q5000 at a wavelength of $280 \mathrm{~nm}$ (Quawell, Sunnyvale, CA). Sodium phosphate buffer $\left(0.2 \mathrm{M} \mathrm{Na}_{2} \mathrm{HPO}_{4}, 0.2 \mathrm{M} \mathrm{NaH}_{2} \mathrm{PO}_{4}, 2\right.$ $\mathrm{m} M$ EDTA, $\mathrm{pH}$ 7.4) was used in this assay.

Then, a sample of $200 \mu \mathrm{L}$ of cell-free extract or buffer as reference was treated with $200 \mu \mathrm{L}$ of freshly prepared DPPH solution $(0.2 \mathrm{~m} M$ in alcohol $)$ in the absence of light. After incubation of $30 \mathrm{~min}$, the reaction mixture was centrifuged at $13,000 \times g$ for $10 \mathrm{~min}$ at room temperature, and the suspension was obtained. The scavenged DPPH was then monitored by measuring the reduction in absorbance at $517 \mathrm{~nm}$. The DPPH scavenging ability was defined as follows: $\left[1-A_{517}\right.$ (sample) $/ \mathrm{A}_{517}$ (reference) $] \times 100$.

\section{Epithelial Cell Lines and Culture Conditions}

The HT-29 human colonic epithelial cell line was used in this study. The cells were grown in RPMI 1640 medium (Hyclone, Logan, UT) containing 10\% (vol/vol) fetal calf serum (FBS; Biological Industries, Kibbutz Beit Haemek, Israel), 1\% (vol/vol) penicillin-streptomycin solution $(100 \mathrm{U} / \mathrm{mL}$ of penicillin and $100 \mu \mathrm{g} /$ $\mathrm{mL}$ of streptomycin, Hyclone) at $37^{\circ} \mathrm{C}$ in a humidified atmosphere in the presence of $5 \% \mathrm{CO}_{2}$. After reaching $80 \%$ confluence, the cells were detached using $0.25 \%$ trypsin-EDTA (Hyclone) and subsequently seeded in 6 -well culture plates at a density of $8 \times 10^{5}$ cells/well for the antioxidant assays. After $24 \mathrm{~h}$ growth, cells were 
washed twice with PBS (Hyclone) and then co-incubated with $1 \times 10^{8} \mathrm{cfu} / \mathrm{mL}$ of $S$. thermophilus strains (optical density at $600 \mathrm{~nm}$ of $0.6-0.8$ ) in FBS-free medium for $2 \mathrm{~h}$ under the conditions described above for the following experiments. Cells in fresh medium without FBS were regarded as control.

\section{Measurement of Intracellular SOD, GSH-px, and CAT}

For these assays, S. thermophilus-treated cells were washed twice and then incubated in $2 \mathrm{~mL}$ of fresh medium without FBS containing $2 \mathrm{mM} \mathrm{H}_{2} \mathrm{O}_{2}$ for 30 min to induce oxidative stress. After the treatment, the cells were washed twice and lysed using cell lysis buffer with $1 \mathrm{~m} M$ phenylmethylsulfonyl fluoride (Beyotime Biotechnology, Shanghai, China). The lysates were collected by scraping from the plates and centrifuged at $13,000 \times g$ at $4^{\circ} \mathrm{C}$ for $5 \mathrm{~min}$. The supernatants were used for further determination of SOD, GSH-px, and CAT immediately. The activities of SOD, GSH-px, and CAT level were measured using the corresponding activity assay kits (Nanjing Jiancheng Bioengineering Corporation, Nanjing, China) according to the commercial instructions (http://www.njjcbio.com/ uploadfile/product/big/20180503153958447.pdf). Protein concentration in the supernatant was determined by the UV-Vis Spectrophotometer at Q5000 at a wavelength of $280 \mathrm{~nm}$.

\section{Measurement of Intracellular ROS}

The intracellular ROS was detected according to a method described previously with minor modifications (Li and Shah, 2016). Briefly, after co-incubation with $S$. thermophilus strains, the oxidative burst was induced by $\mathrm{H}_{2} \mathrm{O}_{2}$ at a final concentration of $2 \mathrm{mM}$ for $30 \mathrm{~min}$ and quantified using flow cytometry as a measure of ROS production following $\mathrm{H}_{2} \mathrm{O}_{2}$ activation. The assay depends upon the cell incorporating DCFH-DA at a final concentration of $10 \mu M$ as a stable nonfluorescent probe. The 2,7-dichlorodihydrofluorescein diacetate (DCFH-DA) was cleaved in DCFH by cellular esterase and then oxidized to the fluorescent dichlorofluorescein under the action of ROS. The cells were then harvested by trypsin and washed with PBS to remove excess DCFH-DA. Then, the fluorescence data of 10,000 cells were recorded for flow cytometry (ImageStreamX Mark II, Amnis, Seattle, WA). Results were expressed as mean fluorescence intensity.

\section{Immunoblotting for Nrf2 Expression}

After co-incubation with bacterial strains, the cells were washed twice and lysed by the methods described above. Equal amounts of cellular protein samples (typically $30 \mathrm{ng}$ ) were separated by $10 \%$ SDS-PAGE and transferred to polyvinylidene difluoride membranes (Solarbio, Beijing, China) for $2 \mathrm{~h}$. After being blocked with Tris-buffered saline with polysorbate 20 containing 5\% nonfat dried milk (Becton, Dickinson and Co., Sparks, MD) for $1 \mathrm{~h}$ at room temperature, the membranes were incubated overnight at $4^{\circ} \mathrm{C}$ with a rabbit polyclonal antibody against $\mathrm{Nrf} 2$ and $\beta$-actin as reference (1:1,000 dilution) and subsequently probed with horseradish peroxidase-conjugated anti-rabbit IgG (1:5,000 dilution) for $1 \mathrm{~h}$ at room temperature. The bands were visualized by enhanced chemiluminescence agents.

\section{Analysis of The Gene Transcriptions by Real-Time PCR}

After co-incubation with bacterial strains, the total RNA of the cells was extracted using an RNA Simple total RNAprep Pure Cell/Bacteria kit (Tiangen, Beijing, China) according to the manufacturer's protocols (http://www.tiangen.com/asset/imsupload/ up0015629001467351068.pdf). The appropriate mass of the total RNA was subjected to perform reverse transcription to synthesize cDNA, using a PrimeScript RT reagent kit (Takara, Shiga, Japan) according to the manufacturer's instructions (http://www.takarabiomed .cn/DownLoad/RR047A.pdf). To quantify the gene transcription level, real-time quantitative PCR was carried out with SYBR Premix Ex TaqII (Takara) using a thermal cycler (Bio-Rad Laboratories, Hercules, CA) according to the manufacturer's protocols. The primer pairs used for real-time quantitative PCR are shown in Table 1. Relative expression level for each gene was normalized against $\beta$-actin as an internal standard and calculated by the comparative threshold cycle $\left(\mathrm{C}_{\mathrm{T}}\right)$ method $\left(2^{-\Delta \Delta \mathrm{CT}}\right)$.

\section{Statistical Analysis}

Experimental data were reported as the mean \pm standard deviation. Statistical significance between treatment and control conditions was assessed by 1-way ANOVA and unpaired 2-tailed Student's t-tests. Probability values $<0.05$ were considered statistically significant.

\section{RESULTS}

\section{Characterization of EfeB Against Oxidative Stress}

To investigate the effect of EfeB on defending oxidative stress, the efeB-deficient mutant ST1314 was 


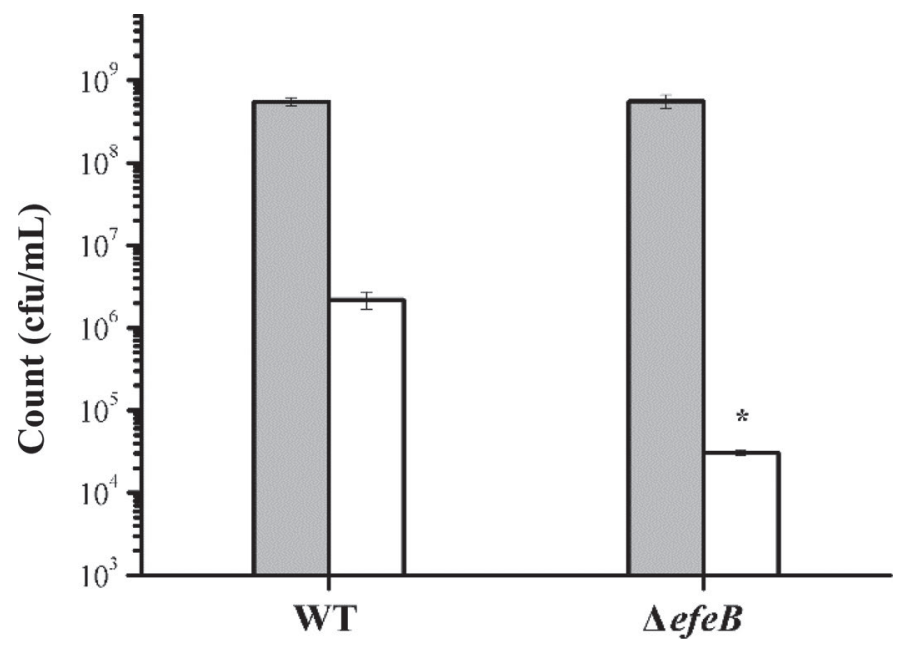

Figure 1. Cell survival of Streptococcus thermophilus CGMCC $7.179(\mathrm{WT})$ and ST1314 $(\Delta e f e B)$ under normal growth conditions

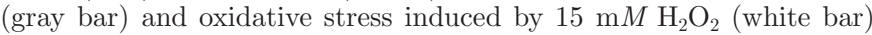
was determined in M17 broth (Oxoid, Basingstoke, United Kingdom) supplemented with $1 \%$ (wt/vol) of lactose (LM17 broth). Data are shown as the mean $\pm \mathrm{SD}, \mathrm{n}=3$. Asterisks represent a statistically significant difference compared with WT under oxidative stress $\left({ }^{*} P\right.$ $<0.05)$.

constructed in S. thermophilus CGMCC 7.179 by homologous double-crossover recombination (Zhang et al., 2015). Zhang et al. (2015) showed that strain ST1314 resulted in decreased growth of the strain CGMCC 7.179 at aerobic conditions. To further confirm the protective effect of EfeB against oxidative stress, the cell viabilities of $S$. thermophilus CGMCC 7.179 and ST1314 were determined under $15 \mathrm{mM} \mathrm{H}_{2} \mathrm{O}_{2}$-induced oxidative stress. The results showed no change between the 2 strains without oxidative stress, whereas the cell viability of strain ST1314 was 2 orders of magnitude lower than strain CGMCC 7.179 under $\mathrm{H}_{2} \mathrm{O}_{2}$-induced oxidative stress (Figure 1).

To further investigate the antioxidant properties of $S$. thermophilus CGMCC 7.179 conferred by EfeB, the capabilities of DPPH radical scavenging of strain CGMCC 7.179 and ST1314 were determined. The results showed that DPPH scavenging activities of strain ST1314 declined from 50\% of strain CGMCC 7.179 to $43 \%$ (Figure 2).

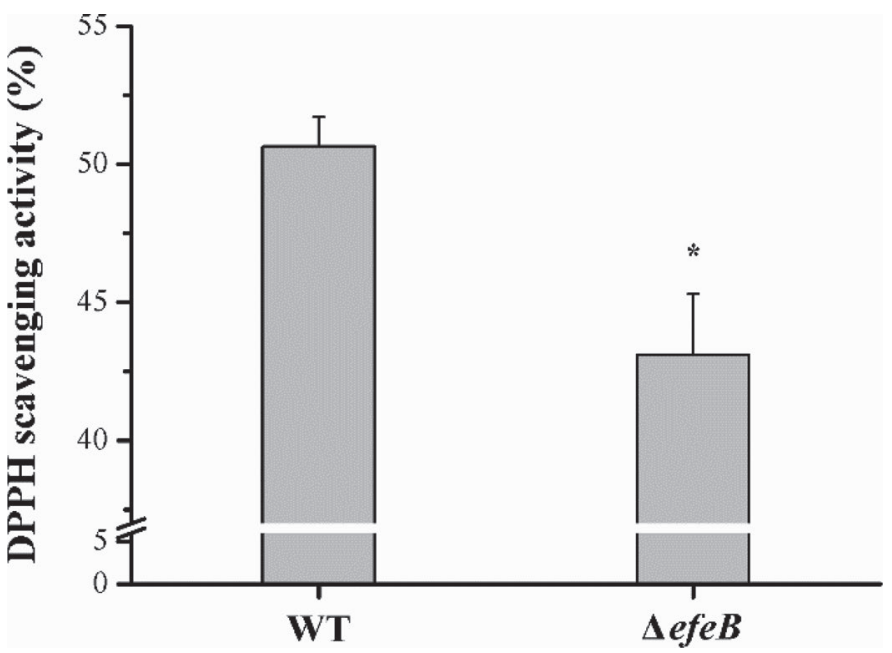

Figure 2. The scavenging activity of Streptococcus thermophilus CGMCC 7.179 (WT) and ST1314 ( $\Delta$ efeB) on 1,1-diphenyl-2-picrylhydrazyl (DPPH) radical was detected. Values are expressed as mean \pm $\mathrm{SD}, \mathrm{n}=3 .{ }^{*}$ Significantly lower than WT strain at $P<0.05$.

\section{Antioxidant Enzyme Activities in S. thermophilus- Treated HT-29 Cells}

To investigate the effect of $S$. thermophilus CGMCC 7.179 on antioxidant activity in intestinal epithelial cells, the intracellular activities of 3 antioxidant enzymes in HT-29 cells were evaluated under $2 \mathrm{mM}$ $\mathrm{H}_{2} \mathrm{O}_{2}$-induced oxidative stress. First, the concentration of $\mathrm{H}_{2} \mathrm{O}_{2}$ used was determined by preliminary experiments: concentrations of $\mathrm{H}_{2} \mathrm{O}_{2}$ ranging from $10 \mu M$ to $5 \mathrm{~m} M$ were analyzed for the HT-29 cell line, and $2 \mathrm{mM}$ induced maximal oxidative burst, whereas cell viability was maintained at $70 \%$ (data not shown). The effect of strain CGMCC 7.179 on SOD activity in HT-29 cells is shown in Figure 3A. When exposed to $\mathrm{H}_{2} \mathrm{O}_{2}$ alone, the activity of SOD sharply decreased from $7.55 \mathrm{U} /$ $\mathrm{mg}$ of protein in the normal cells to $4.69 \mathrm{U} / \mathrm{mg}$ of protein. When co-incubated with strain CGMCC 7.179, SOD activity reached $8.19 \mathrm{U} / \mathrm{mg}$ of protein, a 1.7-fold increase compared with those of $\mathrm{H}_{2} \mathrm{O}_{2}$-treated cells, whereas SOD activity of strain ST1314 treatment was $5.67 \mathrm{U} / \mathrm{mg}$ of protein, $30 \%$ lower than strain CGMCC 7.179. The tert-butylhydroquinone $(100 \mu M)$, a syn-

Table 1. Real-time quantitative PCR primers used for quantification of human mRNA

\begin{tabular}{|c|c|c|}
\hline $\begin{array}{l}\text { Gene } \\
\text { name }\end{array}$ & Forward (from $5^{\prime}$ to $3^{\prime}$ ) & Reverse (from $5^{\prime}$ to $3^{\prime}$ ) \\
\hline Nrf2 & ACACGGTCCACAGCTCATC & TGTCAATCAAATCCATGTCCTG \\
\hline$H O 1$ & СТТСТТСАССТТССССААСА & AGCTCCTGCAACTCCTCAAA \\
\hline$G C L C$ & GGAGACCAGAGTATGGGAGTT & CCGGCGTTTTCGCATGTTG \\
\hline NQO1 & ATGTATGACAAAGGACCCTTCC & TCCCTTGCAGAGAGTACATTGG \\
\hline TXNRD1 & ATATGGCAAGAAGGTGATGGTCC & GGGCTTGTCCTAACAAAGCTG \\
\hline$A C T B$ & AGTTGCGTTACACCCTTTCTTG & TCACCTTCACCGTTCCAGTTT \\
\hline
\end{tabular}


thetic antioxidant, was used as a positive control in these experiments (Abiko et al., 2011).

To further confirm the effect of $S$. thermophilus CGMCC 7.179 on antioxidant enzyme activity in HT29 cells, the GSH-px activity was determined in strain CGMCC 7.179 and ST1314-treated HT-29 cells under 2 $\mathrm{mM} \mathrm{H} \mathrm{H}_{2} \mathrm{O}_{2}$, respectively. As shown in Figure 3B, the intracellular GSH-px level in $\mathrm{H}_{2} \mathrm{O}_{2}$-treated cells decreased about 2-fold compared with the normal cells, whereas the GSH-px activity in strain CGMCC 7.179-treated cells was noticeably enhanced 1.5 -fold compared with $\mathrm{H}_{2} \mathrm{O}_{2}$-treated cells. However, strain ST1314-treated cells failed to increase the level of GSH-px.

In addition, CAT activity was assayed. Treatment of $2 \mathrm{mM} \mathrm{H} \mathrm{H}_{2} \mathrm{O}_{2}$ caused a prominent decline in CAT activity in HT-29 cells, whereas co-incubation with $S$. thermophilus CGMCC 7.179 significantly enhanced the CAT activity 3-fold compared with the $\mathrm{H}_{2} \mathrm{O}_{2}$ group, and the CAT activity of strain ST1314 treatment was not increased (Figure 3C).

\section{Determination of Intracellular ROS Production}

To assess the capability of S. thermophilus CGMCC 7.179 to reduce $\mathrm{H}_{2} \mathrm{O}_{2}$-induced intracellular ROS generation, the level of ROS formation in HT-29 cells was monitored using the dichlorofluorescein fluorescence probe, which was directly proportional to ROS content. The oxidative burst was induced by $\mathrm{H}_{2} \mathrm{O}_{2}$ at a concentration of $2 \mathrm{mM}$. As shown in Figure 4, when

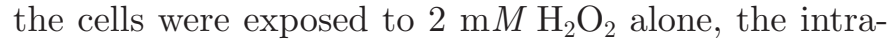
cellular ROS level was increased 2-fold compared with the endogenous ROS production, and a $20 \%$ reduction of the ROS amounts was observed in HT-29 cells coincubated with strain CGMCC 7.179 compared with $\mathrm{H}_{2} \mathrm{O}_{2}$ alone, whereas this reduction of ROS was not obvious in strain ST1314-treated cells. These results indicated that $S$. thermophilus CGMCC 7.179 could attenuate $\mathrm{H}_{2} \mathrm{O}_{2}$-induced ROS production in the presence of EfeB.

\section{Effect of S. thermophilus CGMCC 7.179 on Cellular Expression of Nrf2 Protein}

To clarify whether the antioxidant effect of $S$. thermophilus CGMCC 7.179 for the host cells was due to activation of the Nrf2, a master regulator in the cellular antioxidant systems, Nrf2 protein level was determined by immunoblotting. The results showed that co-incubation with strain CGMCC 7.179 promoted Nrf2 protein level 1.4-fold compared with the normal group in HT29 cells, whereas no obvious change was observed in Nrf2 protein level of strain ST1314-treated HT-29 cells (Figure 5A).
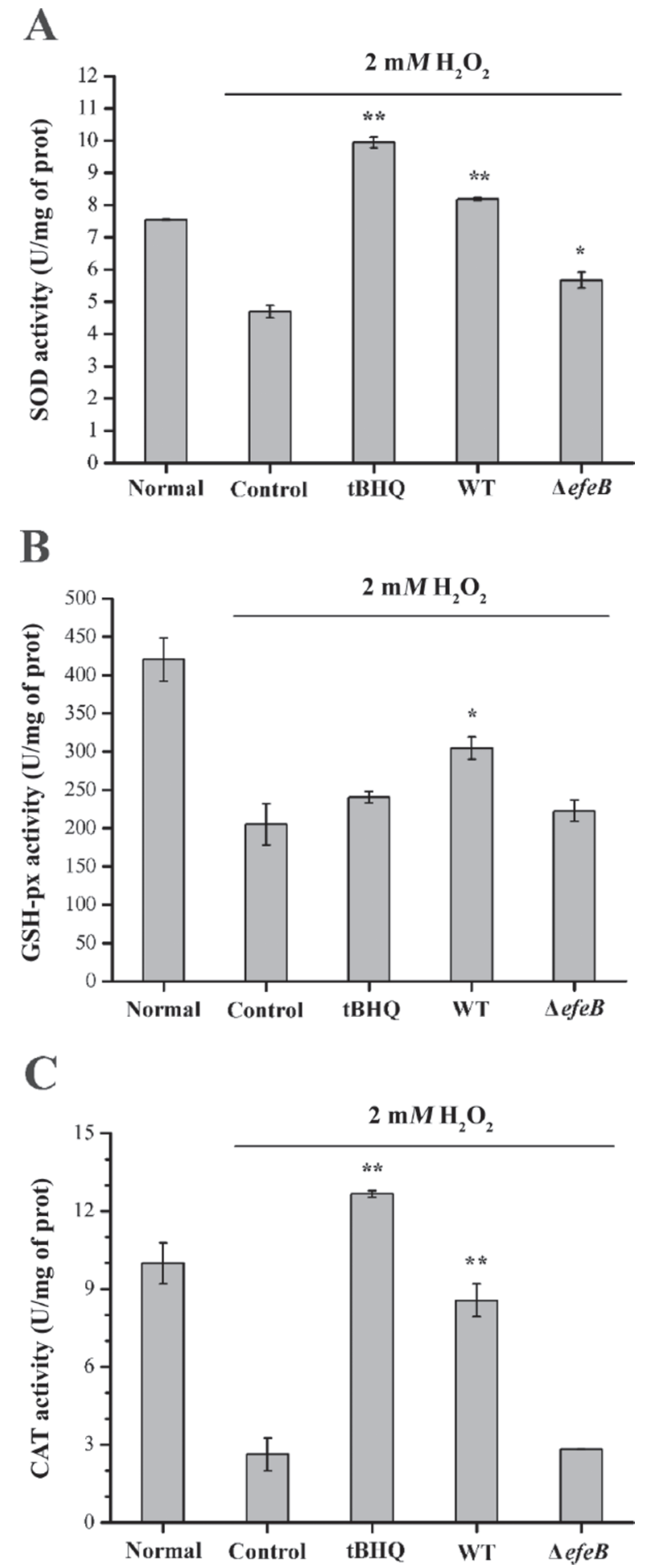

Figure 3. Effects of Streptococcus thermophilus CGMCC 7.179 on superoxide dismutase (SOD) activity (A), glutathione peroxidase (GSH-px) activity (B), and catalase (CAT) activity (C) in HT-29 cells. The HT-29 cells were co-incubated with positive control [tertbutylhydroquinone (tBHQ)], strain CGMCC 7.179 (WT), and ST1314 $(\Delta$ efe $B)$ in the presence of $\mathrm{H}_{2} \mathrm{O}_{2}$. Values are expressed as mean $\pm \mathrm{SD}$, $\mathrm{n}=3$. The normal group represented the cells with no treatment. The control group represented the cells incubated with $\mathrm{H}_{2} \mathrm{O}_{2}$ alone. Asterisks represent a statistically significant difference compared with the control group $\left({ }^{*} P<0.05 ;{ }^{*} P<0.01\right)$. prot $=$ protein. 


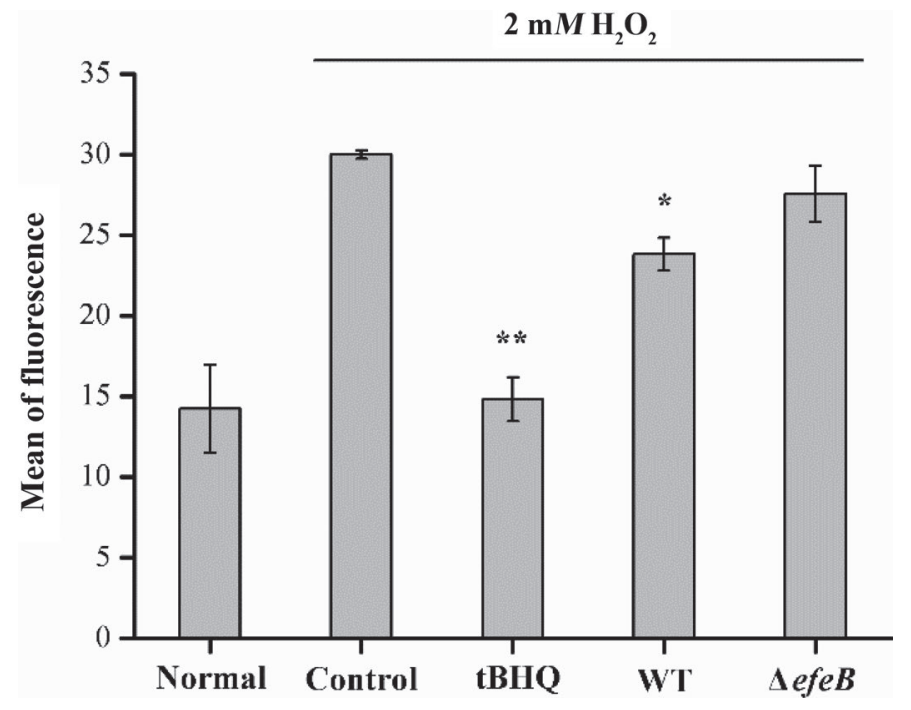

Figure 4. Effects of Streptococcus thermophilus CGMCC 7.179 on $\mathrm{H}_{2} \mathrm{O}_{2}$-induced reactive oxygen species production in HT-29 cells by flow cytometry analysis. The HT-29 cells were co-incubated with positive control [tert-butylhydroquinone (tBHQ)], strain CGMCC 7.179 (WT), and ST1314 $(\Delta e f e B)$, in the presence of 2,7-dichlorodihydrofluorescein diacetate (DCFH-DA) and $\mathrm{H}_{2} \mathrm{O}_{2}$. The normal group used cells incubated with DFCH-DA alone (no stress induction); the control group used cells incubated with DFCH-DA and $\mathrm{H}_{2} \mathrm{O}_{2}$ (stress induction). Values are expressed as mean $\pm \mathrm{SD}, \mathrm{n}=3$. Asterisks represent a statistically significant difference compared with the control group $\left({ }^{*} P<0.05 ;{ }^{* *} P<0.01\right)$.

\section{Effect of S. thermophilus CGMCC 7.179 on Gene Expression of Antioxidant Enzymes}

To further verify the antioxidant effect of $S$. thermophilus CGMCC 7.179 mediated by Nrf2, the gene expressions of several antioxidant enzymes regulated by Nrf2 were evaluated in HT-29 cells. The results first showed that the transcription level of $\mathrm{Nrf2}$ gene in HT-29 cells co-incubated with strain CGMCC 7.179 was 2-fold higher than normal group, whereas strain ST1314 treatment did not show this enhancement (Figure 5B). Additionally, following strain CGMCC 7.179 treatment, the mRNA expressions of other antioxidant enzymes including HO1, GCLC, NQO1, and TXNRD1 were significantly increased, and not promoted obviously in strain ST1314-treated HT-29 cells as we hypothesized (Figure 6).

\section{DISCUSSION}

Accumulated evidence revealed that LAB exerts multiple biological roles through several mechanisms, the antioxidant activity being one of the most debated (Rossi and Amaretti, 2010). In fact, among various beneficial effects for LAB, the cytoprotective effect against oxidative stress was focused on in previous
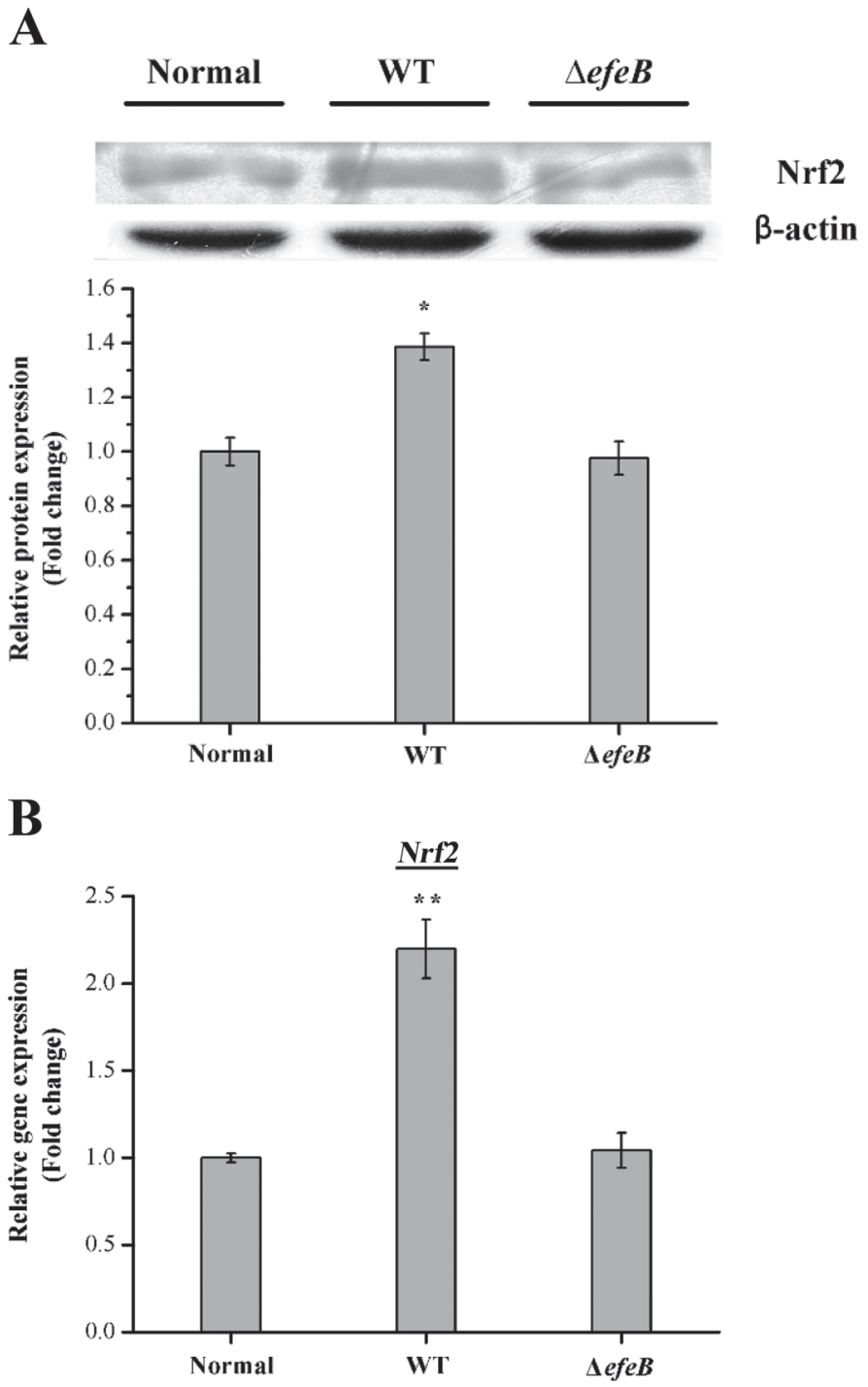

Figure 5. Effect of Streptococcus thermophilus CGMCC 7.179 on the cellular nuclear factor erythroid 2-related factor 2 (Nrf2) protein level as determined by immunoblot analysis (A) and transcription level of the Nrf2 gene as determined by real-time quantitative PCR (B). The HT-29 cells were co-incubated with strain CGMCC 7.179 (WT) and ST1314 $(\Delta e f e B)$ for $2 \mathrm{~h}$. Relative protein content and gene transcription level were presented as the fold change relative to the normal group, respectively. The $\beta$-actin was used as an internal reference. Data are shown as the mean $\pm \mathrm{SD}, \mathrm{n}=3$. Asterisks represent a statistically significant difference compared with the normal group $\left({ }^{*} P\right.$ $\left.<0.05 ;{ }^{* *} P<0.01\right)$.

studies (Songisepp et al., 2005; Virtanen et al., 2007). In this study, we found that $S$. thermophilus CGMCC 7.179 with EfeB activity, which endowed the strain with antioxidant effects, could stimulate the activities of antioxidant enzymes (SOD, GSH-px, and CAT) in human intestinal epithelial cells HT-29, and effectively attenuate intracellular ROS overproduction. Furthermore, in the presence of EfeB, the protein level of Nrf2 and the transcription level of Nrf2-related antioxidant 

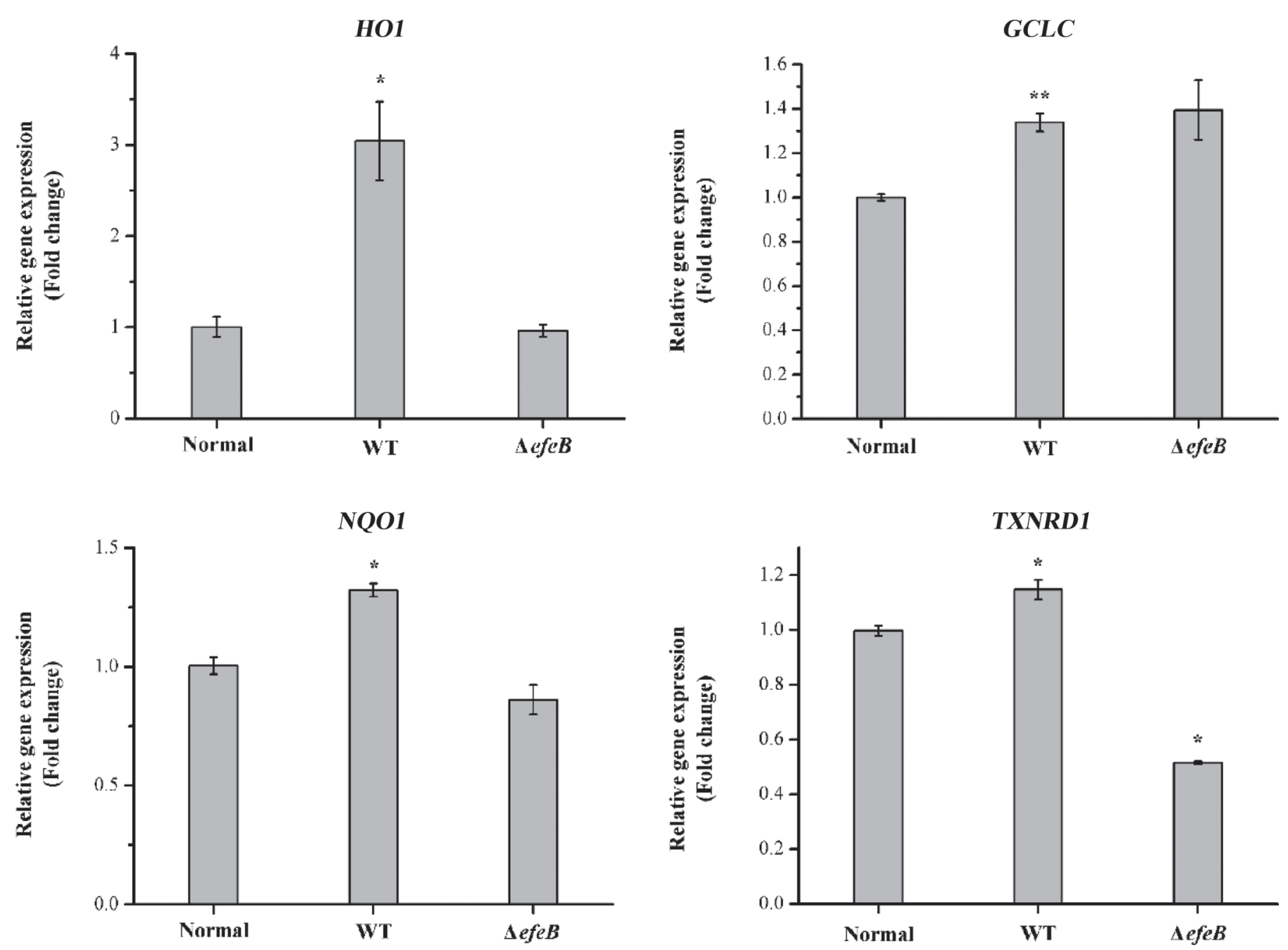

Figure 6. Effects of Streptococcus thermophilus CGMCC 7.179 on gene expression of antioxidant enzymes. The gene transcription levels of the antioxidant enzymes HO1, GCLC, NQO1, and TXNRD1 were evaluated after co-incubation with strain CGMCC 7.179 (WT) and ST1314 $(\Delta e f e B)$ for $2 \mathrm{~h}$. Relative gene expression levels were presented as the fold change relative to the normal group. Data are shown as the mean \pm $\mathrm{SD}, \mathrm{n}=3$. Asterisks represent a statistically significant difference compared with the normal group $\left({ }^{*} P<0.05 ;{ }^{* *} P<0.01\right)$.

enzyme genes were significantly increased in HT-29 cells co-incubated with $S$. thermophilus CGMCC 7.179, suggesting that $S$. thermophilus CGMCC 7.179 with EfeB was able to accomplish the function of antioxidant effects for host cells by controlling the Nrf2 pathway.

As the second most important starter species used in dairy industry after Lactococcus lactis, about $10^{21}$ live cells of $S$. thermophilus were ingested by humans in a previous study (Hols et al., 2005). Therefore, except for the excellent character of fermentation and flavor formation, $S$. thermophilus has several probiotic properties in human gastrointestinal cells. Li and Shah (2017) reported that EPS with sulfonated modification from $S$. thermophilus was effective in improving antioxidant activities. Based on these, we set out to investigate the mechanism of antioxidant activity of $S$. thermophilus for human intestinal epithelial cells. It has been reported that LAB-producing antioxidant enzymes such as SOD and CAT can enhance the cellular antioxidant and anti-inflammatory activity (Bruno-Barcena et al., 2004; Del Carmen et al., 2014), suggesting that the antioxidant effect of LAB may be related to the expression of antioxidant enzymes. Our previous study has identified a novel dye-decolorizing peroxidase EfeB in S. thermophilus CGMCC 7.179, which could provide protection when grown at aerobic conditions. The $\mathrm{H}_{2} \mathrm{O}_{2}$ stress assay in our study further confirmed that this enzyme played a protective role against oxidative stress in S. thermophilus CGMCC 7.179. The DPPH assay has been widely used to estimate the free radical scavenging effectiveness of various antioxidant substances, and it is regarded as an indicator of antioxidant activity evalu- 
ation for LAB. That DPPH scavenging activities of strain ST1314 were lower than that of strain CGMCC 7.179 , suggesting that EfeB plays an important role in antioxidant activity of $S$. thermophilus CGMCC 7.179.

Oxidative stress mainly presents as the overproduction of intracellular ROS. It has been reported that a SOD-producing recombinant Lactobacillus casei BL23 strain could attenuate ROS generation, demonstrating the antioxidant effect of $L b$. casei expressing MnSOD in cellular models under oxidative stress (Watterlot et al., 2010). Our result also proved that in the presence of EfeB, S. thermophilus CGMCC 7.179 could relieve ROS production in intestinal epithelial cells. In addition, SOD, GSH-px, and CAT are known to be the 3 primary antioxidant enzymes in all oxygen metabolizing cells to coordinate intracellular redox homeostasis and eliminate excessive ROS. Thus, the activities of SOD, GSH$\mathrm{px}$, and CAT were determined to evaluate the changes of antioxidant status in the cells. Our results showed that $S$. thermophilus CGMCC 7.179 was capable of enhancing the activities of antioxidant enzymes in human intestinal epithelial cells, whereas strain ST1314 did not exhibit significant enhancement, indicating that S. thermophilus CGMCC 7.179 with EfeB activity had the capability to protect cells against oxidative damage via increasing SOD, GSH-px, and CAT activities, and it was able to regulate the balance of oxygenation effectively in the cells under oxidative stress.

The Nrf2 serves as master regulator of a cellular defense system against oxidative stress, controlling the expression of multiple antioxidant enzymes with an ARE in their promotor regions (Jaiswal, 2004). Under normal conditions, Nrf2 is suppressed by binding to the Kelch-like ECH-associated protein 1 and localized in the cytoplasm in an inactive form, followed by ubiquitin-dependent proteasomal degradation. Under oxidative stress, conformational changes caused by electrophilic xenobiotics or oxidation products in Kelch-like ECH-associated protein 1 lead to the release of Nrf2, thus removing it from degradation. Subsequently, Nrf2 translocates into the nucleus where it binds to the ARE of antioxidant and phase II detoxification enzyme genes to activate their expression and activity (Taguchi et al., 2011). The transcriptional activation of more than 200 antioxidant and protective genes may be controlled by Nrf2. As we know, the Nrf2-ARE pathway is responsible for stimulating SOD, GSH-px, and CAT expression, and hence constitutes a crucial cellular response to oxidative stress (Surh et al., 2009). Therefore, we speculated that the antioxidant effect of $S$. thermophilus CGMCC 7.179 mediated by EfeB was associated with the activation of Nrf2. As expected, the immunoblotting data clearly showed that the $S$. thermophilus CGMCC 7.179 treatment promoted the protein expres- sion of Nrf2 in HT-29 cells, whereas strain ST1314 also failed to show an increase, suggesting that this strain was capable of activation of Nrf2 mediated by EfeB. Additionally, S. thermophilus CGMCC 7.179 with EfeB activity increased the transcription levels of antioxidant enzymes in HT-29 cells as well as enhanced Nrf2 protein level, further demonstrating that the strain conferred a higher antioxidant protection for host cells through the Nrf2 pathway by the function of EfeB.

\section{CONCLUSIONS}

To our knowledge, this is the first time that cytoprotective effect against oxidative stress has been achieved for S. thermophilus carrying a novel peroxidase, EfeB. Our findings suggest that $S$. thermophilus CGMCC 7.179 that express EfeB and that are able to modulate antioxidant responses by Nrf2 could be useful in the development of functional products for the food industry with beneficial effects.

\section{ACKNOWLEDGMENTS}

This work was supported by a grant from the National Natural Science Foundation of China (31471715), National Key Research and Development Program of China (2017YFD0400300), and Public Service Sectors (Agriculture) Special and Scientific Research Projects (201503134; Beijing).

\section{REFERENCES}

Abiko, Y., T. Miura, B. H. Phuc, Y. Shinkai, and Y. Kumagai. 2011. Participation of covalent modification of Keap1 in the activation of Nrf2 by tert-butylbenzoquinone, an electrophilic metabolite of butylated hydroxyanisole. Toxicol. Appl. Pharmacol. 255:32-39.

Berlett, B. S., and E. R. Stadtman. 1997. Protein oxidation in aging, disease, and oxidative stress. J. Biol. Chem. 272:20313-20316.

Bonnefont-Rousselot, D., J. P. Bastard, M. C. Jaudon, and J. Delattre. 2000. Consequences of the diabetic status on the oxidant/ antioxidant balance. Diabetes Metab. 26:163-176.

Bruno-Barcena, J. M., J. M. Andrus, S. L. Libby, T. R. Klaenhammer, and H. M. Hassan. 2004. Expression of a heterologous manganese superoxide dismutase gene in intestinal lactobacilli provides protection against hydrogen peroxide toxicity. Appl. Environ. Microbiol. 70:4702-4710. https://doi.org/10.1128/AEM.70.8.4702-4710 2004 .

Chang, S. K., and H. M. Hassan. 1997. Characterization of superoxide dismutase in Streptococcus thermophilus. Appl. Environ. Microbiol. 63:3732-3735.

Del Carmen, S., A. D. M. de LeBlanc, R. Martin, F. Chain, P. Langella, L. G. Bermdez-Humaín, and J. G. LeBlanc. 2014. Genetically engineered immunomodulatory Streptococcus thermophilus strains producing antioxidant enzymes exhibit enhanced anti-inflammatory activities. Appl. Environ. Microbiol. 80:869-877.

Elli, M., M. L. Callegari, S. Ferrari, E. Bessi, D. Cattivelli, S. Soldi, L. Morelli, N. G. Feuillerat, and J. M. Antoine. 2006. Survival of yogurt bacteria in the human gut. Appl. Environ. Microbiol. 72:5113-5117.

Halliwell, B. 2009. The wanderings of a free radical. Free Radic. Biol. Med. 46:531-542. 
Hols, P., F. Hancy, L. Fontaine, B. Grossiord, D. Prozzi, N. LeblondBourget, B. Decaris, A. Bolotin, C. Delorme, S. D. Ehrlich, E. Guédon, V. Monnet, P. Renault, and M. Kleerebezem. 2005. New insights in the molecular biology and physiology of Streptococcus thermophilus revealed by comparative genomics. FEMS Microbiol. Rev. 29:435-463.

Jaiswal, A. K. 2004. Nrf2 signaling in coordinated activation of antioxidant gene expression. Free Radic. Biol. Med. 36:1199-1207.

Kruidenier, L., and H. W. Verspaget. 2002. Review article: Oxidative stress as a pathogenic factor in inflammatory bowel diseaseradicals or ridiculous? Aliment. Pharmacol. Ther. 16:1997-2015.

Li, S., and N. P. Shah. 2016. Anti-inflammatory and anti-proliferative activities of natural and sulphonated polysaccharides from Pleurotus eryngii. J. Funct. Foods 23:80-86.

Li, S., and N. P. Shah. 2017. Sulphonated modification of polysaccharides from Pleurotus eryngii and Streptococcus thermophilus ASCC 1275 and antioxidant activities investigation using CCD and Caco2 cell line models. Food Chem. 225:246-257.

Lin, M. Y., and F. Y. Chang. 2000. Antioxidative effect of intestinal bacteria Bifidobacterium longum ATCC 15708 and Lactobacillus acidophilus ATCC 4356. Dig. Dis. Sci. 45:1617-1622.

Lu, J., and A. Holmgren. 2014. The thioredoxin antioxidant system. Free Radic. Biol. Med. 66:75-87. https://doi.org/10.1016/j freeradbiomed.2013.07.036.

Marco, S., R. Rullo, A. Albino, M. Masullo, E. de Vendittis, and M. Amato. 2013. The thioredoxin system in the dental caries pathogen Streptococcus mutans and the food-industry bacterium Streptococcus thermophilus. Biochimie 95:2145-2156. https://doi.org/10 .1016/j.biochi.2013.08.008.

Martarelli, D., M. C. Verdenelli, S. Scuri, M. Cocchioni, S. Silvi, C. Cecchini, and P. Pompei. 2011. Effect of a probiotic intake on oxidant and antioxidant parameters in plasma of athletes during intense exercise training. Curr. Microbiol. 62:1689-1696.

Mater, D. D. G., L. Bretigny, O. Firmesse, M. J. Flores, A. Mogenet, J. L. Bresson, and G. Corthier. 2005. Streptococcus thermophilus and Lactobacillus delbrueckii ssp. bulgaricus survive gastrointestinal transit of healthy volunteers consuming yogurt. FEMS Microbiol. Lett. 250:185-187.

Morelli, L. 2014. Yogurt, living cultures, and gut health. Am. J. Clin. Nutr. 99:1248S-1250S.

Pagnini, C., R. Saeed, G. Bamias, K. O. Arseneau, T. T. Pizarro, and F. Cominelli. 2010. Probiotics promote gut health through stimulation of epithelial innate immunity. Proc. Natl. Acad. Sci. USA 107:454-459.

Rabot, S., J. Rafter, G. T. Rijkers, B. Watzl, and J. M. Antoine. 2010. Guidance for substantiating the evidence for beneficial effects of probiotics: Impact of probiotics on digestive system metabolism. J. Nutr. 140:677S-689S.

Rossi, M., and A. Amaretti. 2010. Probiotic properties of bifidobacteria. Pages 97-123 in Bifidobacteria: Genomics and Molecular Aspects. B. Mayo and D. van Sinderen, ed. Caister Academic Press, Norfolk, UK
Savaiano, D. A. 2014. Lactose digestion from yogurt: Mechanism and relevance. Am. J. Clin. Nutr. 99:1251S-1255S.

Songisepp, E., J. Kals, T. Kullisaar, R. Mändar, P. Hütt, M. Zilmer, and M. Mikelsaar. 2005. Evaluation of the functional efficacy of an antioxidative probiotic in healthy volunteers. Nutr. J. 4:22.

Spooner, R., and O. Yilmaz. 2011. The role of reactive-oxygen-species in microbial persistence and inflammation. Int. J. Mol. Sci. $12: 334-352$.

Storz, P. 2005. Reactive oxygen species in tumor progression. Front. Biosci. 10:1881-1896.

Surh, Y. J., J. K. Kundu, M. H. Li, H. K. Na, and Y. N. Cha. 2009 Role of Nrf2-mediated heme oxygenase-1 upregulation in adaptive survival response to nitrosative stress. Arch. Pharm. Res. $32: 1163-1176$

Taguchi, K., H. Motohashi, and M. Yamamoto. 2011. Molecular mechanisms of the Keap1-Nrf2 pathway in stress response and cancer evolution. Genes Cells 16:123-140.

Thibessard, A., A. Fernandez, B. Gintz, N. Leblond-Bourget, and B. Decaris. 2001a. Hydrogen peroxide effects on Streptococcus thermophilus CNRZ368 cell viability. Res. Microbiol. 152:593-596. https://doi.org/10.1016/S0923-2508(01)01234-7.

Thibessard, A., N. Leblond-Bourget, A. Fernandez, B. Gintz, and B. Decaris. 2001b. Response of Streptococcus thermophilus CNRZ368 and its colonial variants to oxidative stress: Evidence for an inducible defence system. Lait 81:311-316. https://doi.org/10.1051/lait: 2001134

Valko, M., D. Leibfritz, J. Moncol, M. T. Cronin, M. Mazur, and J. Telser. 2007. Free radicals and antioxidants in normal physiological functions and human disease. Int. J. Biol. Cell Biol. 39:44-84.

Virtanen, T., A. Pihlanto, S. Akkanen, and H. Korhonen. 2007. Development of antioxidant activity in milk whey during fermentation with lactic acid bacteria. J. Appl. Microbiol. 102:106-115.

Wang, Y., H. Y. He, H. H. Li, W. W. Lu, T. T. Guo, and J. Kong. 2017. The global regulator CodY responds to oxidative stress by the regulation of glutathione biosynthesis in Streptococcus thermophilus. J. Dairy Sci. 100:8768-8775.

Watterlot, L., T. Rochat, H. Sokol, C. Cherbuy, I. Bouloufa, F. Lefevre, J. J. Gratadoux, E. Honvo-Hueto, S. Chilmonczyk, S. Blugeon, G. Corthier, P. Langella, and L. G. Bermudez-Humaran. 2010. Intragastric administration of a superoxide dismutase-producing recombinant Lactobacillus casei BL23 strain attenuates DSS colitis in mice. Int. J. Food Microbiol. 144:35-41.

Zhang, C., Y. P. Xin, Y. Wang, T. T. Guo, S. Y. Lu, and J. Kong. 2015. Identification of a novel dye-decolorizing peroxidase, EfeB, translocated by a twin-arginine translocation system in Streptococcus thermophilus CGMCC 7.179. Appl. Environ. Microbiol. 81:6108-6119.

Zhu, H., and Y. R. Li. 2012. Oxidative stress and redox signaling mechanisms of inflammatory bowel disease: Updated experimental and clinical evidence. Exp. Biol. Med. (Maywood) 237:474-480. 